\title{
Carboplatin-Etoposide-Vincristine Regimen
}

National Cancer Institute

\section{Source}

National Cancer Institute. Carboplatin-Etoposide-Vincristine Regimen. NCI Thesaurus.

Code C129579.

A chemotherapy regimen containing carboplatin, etoposide, and vincristine which may be used in the treatment of pediatric retinoblastoma (RB). 